\title{
Diagnosis and treatment of right ventricular dysfunction in congenital heart disease
}

\author{
Béatrice Santens $^{1,2}$, Alexander Van De Bruaene ${ }^{1,2}$, Pieter De Meester ${ }^{1,2}$, Michele D'Alto ${ }^{3}$, Sushma Reddy $^{4}$, \\ Daniel Bernstein ${ }^{4}$, Martin Koestenberger ${ }^{5}$, Georg Hansmann ${ }^{6}$, Werner Budts ${ }^{1,2}$ \\ ${ }^{1}$ Congenital and Structural Cardiology, University Hospitals Leuven, Leuven, Belgium; ${ }^{2}$ Department of Cardiovascular Sciences, Catholic University \\ Leuven, Leuven, Belgium; ${ }^{3}$ Department of Cardiology, University "L. Vanvitelli" - Monaldi Hospital, Naples, Italy; ${ }^{4}$ Department of Pediatrics \\ (Cardiology), Stanford University, California, United States of America; ${ }^{5}$ Department of Pediatric Cardiology, Medical University Graz, Graz, \\ Austria; ${ }^{6}$ Department of Pediatric Cardiology and Critical care, Hannover Medical School, Hannover, Germany \\ Contributions: (I) Conception and design: B Santens, W Budts, P De Meester, A Van De Bruaene, G Hansmann, M Koestenberger, M D’Alto; (II) \\ Administrative support: B Santens, W Budts, G Hansmann; (III) Provision of study materials or patients: None; (IV) Collection and assembly of data: \\ None; (V) Data analysis and interpretation: None; (VI) Manuscript writing: All authors; (VII) Final approval of manuscript: All authors. \\ Correspondence to: Werner Budts, MD, PhD. University Hospitals Leuven, Herestraat 49, B-3000 Leuven, Belgium. \\ Email: werner.budts@uzleuven.be.
}

\begin{abstract}
Right ventricular (RV) function is important for clinical status and outcomes in children and adults with congenital heart disease (CHD). In the normal RV, longitudinal systolic function is the major contributor to global RV systolic function. A variety of factors contribute to RV failure including increased pressure- or volume-loading, electromechanical dyssynchrony, increased myocardial fibrosis, abnormal coronary perfusion, restricted filling capacity and adverse interactions between left ventricle (LV) and RV. We discuss the different imaging techniques both at rest and during exercise to define and detect RV failure. We identify the most important biomarkers for risk stratification in RV dysfunction, including abnormal NYHA class, decreased exercise capacity, low blood pressure, and increased levels of NTproBNP, troponin T, galectin-3 and growth differentiation factor 15. In adults with CHD (ACHD), fragmented QRS is independently associated with heart failure (HF) symptoms and impaired ventricular function. Furthermore, we discuss the different HF therapies in CHD but given the broad clinical spectrum of CHD, it is important to treat RV failure in a disease-specific manner and based on the specific alterations in hemodynamics. Here, we discuss how to detect and treat RV dysfunction in CHD in order to prevent or postpone RV failure.
\end{abstract}

Keywords: Congenital heart disease (CHD); heart failure (HF); right ventricular dysfunction; systemic right ventricular; treatment of heart failure

Submitted Mar 18, 2020. Accepted for publication May 13, 2020.

doi: $10.21037 / \mathrm{cdt}-20-370$

View this article at: http://dx.doi.org/10.21037/cdt-20-370

\section{Introduction}

To understand the physiology of the morphological right ventricle (RV), it is important to acknowledge that the RV is not just a mirror of the left ventricle (LV). Both ventricles have different embryological origins: the $L V$ originates from the primary heart field (as well as both atria), whereas the truncus arteriosus, the RV and the RV outflow tract come from the secondary heart field (1). The RV is a crescentshape structure wrapped around the left ventricle (which is more bullet shaped) (2).

Furthermore, the RV myocardium is thin $(3-5 \mathrm{~mm})$ and characterized by heavily trabeculated walls. The LV has 3 layers of myofibers, whereas the RV only has 2 layers. The LV subendocardium has longitudinal fibers and a middle layer with circumferential myofibers $(2,3)$. The latter provides the driving force of $\mathrm{LV}$ systolic function whereas the myofibers of the normal, non-hypertrophied RV have no middle layer so that the RV myocytes create predominantly a shortening of the longitudinal axis with traction of the 
tricuspid valve (TV) towards the apex (1). In addition, the $\mathrm{RV}$ has some helical fibers that generate a twisting motion of the RV during systole. The interventricular septum (IVS) shares some myofibers of both the RV and LV, so that contraction of the $\mathrm{RV}$ is influenced by the contraction of the $\mathrm{LV}$. Thus, in the normal RV, systolic function is maintained by mainly longitudinal shortening of the ventricle.

Five characteristic features of the RV can be used to distinguish it from LV: (I) the presence of tendinous cords attaching its septal leaflet to the IVS, (II) the apical displacement of the TV, (III) the moderator band (IV) the rough apical trabeculations and $(\mathrm{V})$ the absence of fibrous continuity between the TV and pulmonary valve (PV). Finally, the right coronary artery provides the major blood supply to the morphological RV (mRV) as well as the inferior wall of the heart. Note that in a normotensive subpulmonary RV, coronary blood flow occurs in systole and diastole, while in the LV it occurs only in diastole. In conditions with elevated or systemic RV pressure, RCA flow occurs only in diastole and this lower coronary supply is even further reduced when right ventricular end-diastolic pressure (RVEDP) is high due either to right ventricular hypertrophy $(\mathrm{RVH})$ or restrictive disease.

RV compliance and pulmonary vascular resistance (PVR) change profoundly postnatally. In the first few months after birth, the subpulmonary $\mathrm{mRV}$ is hypertrophied and restrictive. In infants and small children, the cardiac output is increased predominantly by an increase in heart rate, while the potential of increasing stroke volume (SV) is limited. Over time (beyond infancy, $>1$-year-old), the subpulmonary mRV becomes more compliant, while PVR has usually already decreased to normal values $(<2 \mathrm{WU}$ $\times \mathrm{m}^{2}$ ) by 2 months of life.

In some congenital heart defects, the mRV—and not the morphological LV (mLV)—supports the systemic circulation (so-called "systemic RV", sRV), see Table 1. In that case, when the mRV has systemic pressure afterload and significant RVH, the sRV contractile units change shape and orientation and resemble those of the $L V$ with the typical so-called "sandwich" pattern: predominant circumferential over longitudinal free wall shortening but without any difference in septal shortening, allowing the RV to function as the systemic pump (3). However, the sRV does not show torsion as found in the normal LV (4).

Furthermore, RV contraction is dependent on its volume and pressure loading conditions. In general, the pulmonary circulation is a low-pressure system with low vascular resistance ( $>2-3$ months after the birth). The RV output approximates that of the left but with an energy cost of approximately one-fifth that of the left (5). This is the result of the low-pressure system as well as of the unique characteristics of the RV pressure-volume (PV) loop relationship. In contrast to the $\mathrm{LV}$, which has a rectangular PV loop with well-defined isovolumetric stages, the PV loop of the RV has a trapezoidal shape with short isovolumetric contraction time. As a result of autoregulation, myocardial contractility increases with afterload (the so-called "Anrep effect"), in other words the LV Anrep effect characterizes the increase of $L V$ contractility in response to increased $\mathrm{LV}$ afterload. The RV adapts to an increased afterload in two different ways: (I) increase of myocardial contractility (Anrep effect) and (II) increase of preload autoregulation or Frank-Starling mechanism (6). But very little is known about the Anrep effect in the failing pressure loaded RV (7). The Anrep effect may be the primary mechanism for initial adaptation to pressure overload in the RV but this may be more important in the neonatal than in the adult RV (8).

In older children and adults, the $\mathrm{mRV}$ has a greater compliance with a higher surface area to volume ratio than the $\mathrm{LV}(1,8)$, hence the RV can handle large increases in volume. As a consequence of pressure or volume overload, the $\mathrm{RV}$ remodels, ranging from increased ejection fraction to progressive dilatation and/or hypertrophy $(1,9)$. In addition, the fibrotic response to volume loading is stronger in the RV when compared to the LV (1). Such cardiac remodeling evolves into systolic or diastolic dysfunction of the RV. RV dysfunction is not uncommon in CHD and the first clinical sequelae often occur in adolescents and young adults. Therefore, we will focus on the diagnosis and treatment of RV dysfunction in adolescents and young adults. To enhance outcome in patients with CHD, RV failure needs to be detected and treated at an early stage (10).

\section{Detection of RV dysfunction}

\section{Imaging techniques at rest}

Accurate functional imaging of the RV has long been out of reach due to its complex three-dimensional structure and its hemodynamic variability with diverse loading conditions. Cardiac magnetic resonance (CMR) imaging is still the gold standard for the evaluation of RV morphology, mass, volumes and systolic function. However, assessing both systolic and diastolic RV function and volumes has improved with the introduction of new echocardiographic techniques (11). The different imaging techniques are 
Table 1 Spectrum of the morphological right ventricle in congenital heart disease

1. Subpulmonary RV (pulmonary artery arises from the morphological RV)

a. Pressure loaded RV

(a) Mechanical obstructions in the subpulmonary circulation:

a) Supravalvular pulmonary stenosis

b) Pulmonary valve stenosis

C) Infundibular pulmonary stenosis

d) Double chambered right ventricle

(b) Pulmonary hypertension (including IPAH/HPAH with incidental pre-/post-tricuspid shunt, significant shunt lesions, Eisenmenger syndrome)

b. Volume loaded RV

(a) Pulmonic valve regurgitation (Tetralogy of Fallot)

(b) Tricuspid valve regurgitation (Ebstein anomaly)

(c) ASD

2. Systemic RV (aorta arises from the morphological RV)

a. Biventricular circulation

(a) ccTGA (most common: S.L.L., TGA; less common: I.D.D., TGA)

(b) d-TGA (S.D.D., TGA) after atrial switch repair

b. Univentricular circulation
(a) HLHS
(b) DORV-DIRV with subpulmonary stenosis
(c) (DIRV)

ASD, atrial septal defect; ccTGA, congenitally corrected transposition of the great arteries; DIRV, double inlet right ventricle; DORV, double-outlet right ventricle; d-TGA, dextro-transposition of the great arteries; HLHS, hypoplastisch left heart syndrome; HPAH, hereditary pulmonary arterial hypertension; IPAH, idiopathic pulmonary arterial hypertension; RV, right ventricle.

discussed elsewhere in this special issue (see Truong et al., CDT 2020, in press). Most non-invasive imaging techniques for the RV have been validated in the setting of pulmonary hypertension (PH) (see Jone et al., CDT 2020, in press), with few studies published on the applicability and validation of non-invasive imaging techniques for the RV in the setting of CHD.

\section{Echocardiographic evaluation of the $R V$}

Two-dimensional echocardiography is the first line, easily applicable non-invasive imaging modality for the diagnosis of RV dysfunction. Yet, echocardiography tends to underestimate RV volumes in comparison with CMR (12). The advantages and disadvantages of multiple echocardiographic variables in CHD is reviewed in detail elsewhere (13).

\section{Definition of RV dysfunction on echocardiography}

It can be difficult to quantitate RV dysfunction by echo and thus the diagnosis of RV failure should include multiple variables. Moreover, the time at which RV remodeling evolves into RV failure can be difficult to determine as long as the RV output is maintained. The RV is exquisitely sensitive to its loading conditions, both preload and afterload and the response of the RV to changes in either pressure or volume load is different (14). Acute increases in $\mathrm{RV}$ afterload can cause dramatic reductions in RV output whereas acute increases in volume load are reasonably well tolerated. In response to chronic volume overload, the $\mathrm{RV}$ elongates with septal flattening in diastole, whereas in response to chronic pressure overload there is RV dilatation 
and hypertrophy, with septal flattening during systole.

To determine systolic RV dysfunction on echocardiography, we make use of the definition by a large meta-analysis with patients with HFpEF (were RV dysfunction is highly prevalent) and normal adults, where systolic RV dysfunction was defined as (I) tricuspid annular place systolic excursion (TAPSE) $<17 \mathrm{~mm}$; (II) fractional area change (FAC) $<35 \%$; (III) and/or tricuspid annular systolic velocity $\left(\mathrm{s}^{\prime}\right)<9.5 \mathrm{~cm} / \mathrm{s}(11,15)$.

\section{Systolic RV dysfunction}

In 2010, the American Society of Cardiology (ASE) published guidelines to assess the RV in adults, with an update in 2015. ASE relies on geometric assumptions that are not always applicable in the setting of congenital heart disease (CHD) (14-17). Visual examination (eye-balling) of the RV used as a single parameter to quantify $\mathrm{RV}$ function proved to be inaccurate with both under- and overestimation of the RV function (9). RV evaluation should thus include quantitative measurement of RV size, right atrium (RA) size, RV systolic function [with at least one or a combination of the following parameters: FAC, S', TAPSE, RIMP (Tei index), 3D EF and longitudinal strain and strain rate by TDI], and systolic pulmonary artery pressure (SPAP) with estimate of the RA pressure on the basis of the inferior vena cava (IVC) size and its degree of collapse $(9,15,16)$. The quantification of RV function in CHD patients may be confounded by the specific hemodynamic role of the RV in question, e.g., subaortic RV, a single ventricle $R V, R V$ with large IVS patch (s/p VSD closure) or an RV with a large transannular RVOT patch. Furthermore, due to the post-operative changes in chest anatomy in these patients, estimating the systolic function of the RV is not always easy by 2D echocardiography (17). Whenever feasible, 3D echocardiography should be performed because of the unique and complex anatomy of the RV without the need for geometric assumptions $(9,15,16,18)$. Doppler can be an important adjunct to estimate differences between chamber pressures, to calculate shunt fractions, cardiac output and cardiac index without invasive cardiac catheterization.

For patients with chronic volume/pressure overload and for patients with myocardial disease secondary to the underlying CHD, it is of utmost importance to frequently evaluate and monitor the patient's hemodynamic and clinical condition, and especially detect even subtle changes in RV size and/or function (9).

Increased isovolumic contraction time (IVCT) and isovolumic relaxation time (IVRT) in RV dysfunction lead to prolonged RV systole and shortened RV diastole (19). As a result of prolonged $\mathrm{RV}$ contraction, $\mathrm{RV}$ systole extends into early LV diastole. Loading, pressure and function of one ventricle affects the contralateral ventricle. Due to the Frank-Starling mechanism, increased volume loading on the $\mathrm{RV}$ would be expected to also increase LV SV; in contrast, when RV afterload is significantly increased, RV volume loading can paradoxically reduce LV SV as a result of direct ventricular-ventricular interactions (19). An enlarged RV compresses the $\mathrm{LV}$ and an $\mathrm{RV} / \mathrm{LV}$ dimension ratio $>1$ had been associated with increased mortality risk. In the setting of a systemic RV, dilatation of the sRV compresses the subpulmonary LV, leading to dysfunction.

\section{RV diastolic dysfunction}

Diastolic dysfunction occurs when contractile units do not return to their resting length. Both acute and chronic conditions have been associated with RV diastolic dysfunction, resulting in elevated filling pressures and clinically apparent hepatomegaly or jugular venous distension (16). The ASE guidelines recommend considering measurement of RV diastolic dysfunction in patients with suspected RV dysfunction, or in patients with known RV impairment as a marker of poor prognosis, as diastolic dysfunction may be present despite preserved systolic function. Furthermore, diastolic performance is a potentially more sensitive indicator of cardiovascular pathology than systolic dysfunction because even subtle hypertrophic and fibrotic myocardial remodeling may significantly affect ventricular filling characteristics early on (20). The following 5 variables and ratios have been the most validated measurements to evaluate RV dysfunction in adults with or without $\mathrm{CHD}$ : $\mathrm{E} / \mathrm{A}$ ratio, $\mathrm{E} / \mathrm{E}$ ' ratio, $\mathrm{RA}$ size, deceleration time of the E' wave and IVRT (16). More recently, RA strain as a parameter of RA reservoir function seems to correlate well with exercise capacity (21).

A summary of the available echocardiographic techniques is presented in Table 2, and in other articles $(13,28)$, including Jone et al. CDT, 2020 in this special issue. Abnormal values are listed, but it is important to note that specific reference values for patients with CHD do not exist or are not validated.

\section{PH}

In routine echocardiography, all CHD patients should be screened for the presence of PH $(29,30)$, defined according 
Table 2 Summary of echocardiography imaging techniques

\begin{tabular}{|c|c|c|c|c|}
\hline Parameters & Recommended methods (values RV failure) & Strengths & Limitations & Mortality \\
\hline \multicolumn{5}{|l|}{ Assessment of RV size } \\
\hline $\begin{array}{l}\text { Size } \\
\text { Linear dimensions } \\
\text { 2D volumes }\end{array}$ & $\begin{array}{l}\text { RV focused } 4 \mathrm{CV} \\
\text { Base }(>42 \mathrm{~mm}) \\
\text { Mid }- \text { level }(>35 \mathrm{~mm}) \\
\text { Longitudinal }(>53 \mathrm{~mm}) \text { ED } \\
\text { LV/RV ED ratio }=1.3(9) \\
\text { ED and ES }\end{array}$ & $\begin{array}{l}\text { - Easy to perform } \\
\text {. Fast and simple } \\
\text { - Mid RV diameter always } \\
\text { Mideter and RV length only in right-sided disease }\end{array}$ & $\begin{array}{l}\text { - Underestimated as opposed to cardiac CMR (geometric model) due to } \\
\text { crescent shape }>3 \mathrm{D}(9) \\
\text { Dependent on probe rotation and different RV views } \\
\text { Suboptimal image quality of RV free wall } \\
\text { Presence of trabeculatation } \\
\text { Assessment of ventricular volumes and function: unsatisfying in SRV and } \\
\text { UVH (unique geometry) }\end{array}$ & $\begin{array}{l}\text { LV/RV ratio predictor of adverse clinical } \\
\text { events and/or hospital survival in } \\
\text { patients with acute PE (22) }\end{array}$ \\
\hline RV free-wall thickness & $\begin{array}{l}\text { Subcostal } 4 \mathrm{CV} \text {, zoomed imaging } \\
\mathrm{ED}, \mathrm{M} \text {-mode or } 2 \mathrm{D} \text { [RV free lateral wall }>5 \mathrm{~mm}(9)]\end{array}$ & - Easy to perform & $\begin{array}{l}\text { - Single - site measurement } \\
\text { No criterium for abnormal thin RV wall } \\
\text { Excluding RV trabeculations and papillary muscle from RV endocardial } \\
\text { border is critical } \\
\text { - Lack of established prognostic information } \\
\text { Oblique M-mode may overestimate RV wall }\end{array}$ & Prognostic value unknown \\
\hline RVOT & $\begin{array}{l}- \text { RVOT proximal: } \\
\text { - anterior RV wall - IVS (PLAX) or - aortic valve (PSAX) ED } \\
\text { RVOT distal: measured just proximal to the PV at ED } \\
\text { RVOT dilatation: } \\
\text { - RVOT proximal PLAX }>33 \mathrm{~mm} \\
\text { - } \\
\text { RVOT Distal PSAX }>27 \mathrm{~mm}\end{array}$ & $\begin{array}{l}\text { - Simple } \\
\text { - Fast }\end{array}$ & $\begin{array}{l}\text { - RVOT proximal: imaging plane position and less reproducible than RVOT } \\
\text { - distal } \\
\text { - Enderestimation or overestimation if the RV view is obliquely oriented } \\
\text { - Limited data are availab the RV anterior wall is often suboptimal }\end{array}$ & \\
\hline 3D & 3D volumes & $\begin{array}{l}\text { - Calculates 3D volumes (no geometric assumptions) } \\
\text { - Independent of the RV exact shape } \\
\text { - Correlates with CMR measurements }\end{array}$ & $\begin{array}{l}\text { - Special transducer, dedicated hardware and software } \\
\text { - Higher cost } \\
\text { - Additional time to perform } \\
\text { - } \text { Patient cooperatition } \\
\text { - } 3 \text { D training } \\
\text { - Only few data on reference values available }\end{array}$ & $\begin{array}{l}\text { Independent predictor of adverse } \\
\text { cardiovascular outcome (18) }\end{array}$ \\
\hline \multicolumn{5}{|l|}{ Assessment of RV function } \\
\hline \multicolumn{5}{|l|}{$\begin{array}{l}\text { RV longitudinal systolic } \\
\text { function }\end{array}$} \\
\hline \multirow[t]{2}{*}{ TAPSE } & Apical 4CV & - Validated against radionuclide EF & - 1D measurement & Low TAPSE is associated with lower $\mathrm{Cl}$ \\
\hline & $\begin{array}{l}\text { Maximum systolic excursion of the lateral tricuspid annulus (M-mode) between } \\
\text { ED and peak systole }(<16 \mathrm{~mm})\end{array}$ & & $\begin{array}{l}\text { - Only global RV function } \\
\text { Angle - dependent } \\
\text { Does not reflect true RVEF in patients with TOF and TR }\end{array}$ & $\begin{array}{l}\text { and worse survival (23,24) } \\
\text { TAPSE/SPAP is a good predictor of } \\
\text { survival (25) }\end{array}$ \\
\hline $\begin{array}{l}\text { Tissue doppler of the free } \\
\text { lateral wall (S') }\end{array}$ & $\begin{array}{l}\text { Longitudinal velocity of the tricuspid annular plane (S' value }<0.095 \mathrm{~m} / \mathrm{s} \text { ) } \\
\text { Pulsed tissue doppler }\end{array}$ & $\begin{array}{l}\text { - Reproducible } \\
\text { - Validated against radionuclide EF } \\
\text { - Good correlation with CMR-derived RVEF }\end{array}$ & $\begin{array}{l}\text { - Angle - dependent } \\
\text { - Small subsection of the RV } \\
\text { - Not to apply in case of regional wall-motion abnormalities }\end{array}$ & Established prognostic value \\
\hline $\begin{array}{l}\text { Global Longitudinal strain } \\
\text { (GLS) (RV free wall) } \\
\text { Strain rate }\end{array}$ & $\begin{array}{l}\text { \% systolic shortening of the RV free wall } \\
\text { Average peak systolic strain of the } 3 \text { segments of the free lateral wall } \\
\text { RV focused } 4 \mathrm{CV}(>-20 \%) \\
\text { Rate of this shortening }\end{array}$ & 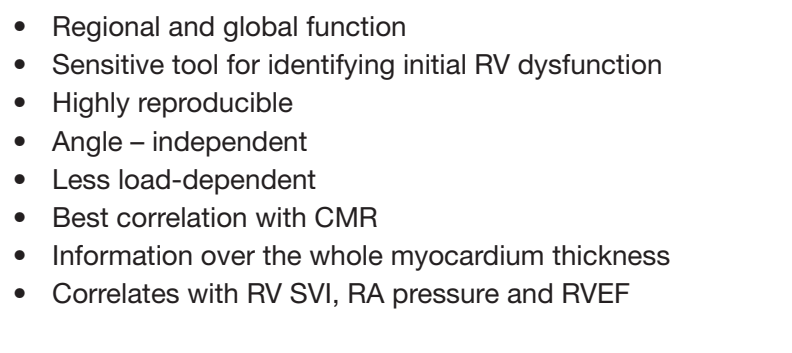 & $\begin{array}{l}\text { - Vendor and software dependent } \\
\text { RV size and shape } \\
\text { Image quality } \\
\text { - Load - dependent (less than PW and TDI) } \\
\text { Strain rate (velocity) is less accurate than time - integrated measures } \\
\text { - RV firain free wall GLS corresponds better with RV mechanical function than } \\
\text { RV global strain (which includes IVS and is part of both ventricles) } \\
\text { - In patients with AF: average of } 3 \text { heart cycles }\end{array}$ & $\begin{array}{l}\text { Excellent predictor of outcome (11) and } \\
\text { survival in PAH-patients (26) }\end{array}$ \\
\hline
\end{tabular}

Table 2 (Continued) 
Table 2 (Continued)

Parameters
RV global systolic function
Recommended methods (values RV failure)

Strengths

Limitations

FAC

100x (RVED - RVES)/RVED

RV focused 4 CV $(<35 \%)$

3D RVEF

Fractional RV volume change

RF EF (\%) $=100 x($ EDV-ESW)/EDV (RVEF $<45 \%)$

Tissue doppler velocities or pulse wave velocities from the RV (IVRT - IVCT)/ RV ejection time (PW doppler $>0.43)($ TDI > 0.54$)$

RIMP (Tei index)

RV diastolic function

Doppler E/A ratio

Doppler E/E' ratio

antegrade flow in the PA

Apical $4 \mathrm{CV}$

- tricuspid E/A ratio <0.8: impaired relaxation

Best correlation with CMR

Includes RVOT contribution to overall function

-tricuspid E/A ratio 0.8-2.1 + E/E'ratio $>6$ or diastolic flow predominance in the - Tricuspid E/E' ratio and RA volume have been shown to hepatic veins: pseudonormal filling tricuspid E/A ratio $>2.1+$ deceleration
late diastolic antegrade flow in the PA

RA size (RA dimensions and Single-plane area-length or disk summation techniques in an apical view

End - diastole/4CV (normal value: women: $21+/-6 \mathrm{~mL} / \mathrm{m}^{2}$ and for men $25+/-7$

$\left.\mathrm{mL} / \mathrm{m}^{2}\right)$

RA length (>53 mm) and RA diameter $(>44 \mathrm{~mm}$

Hepatic veins + measurement Pulsed doppler

of IVC size and collapsibility Low or normal RA pressure: Vs $>$ Vd

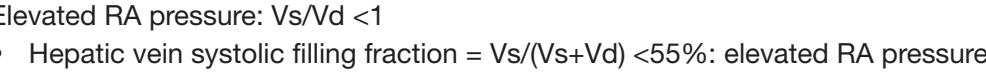

- Normal RA pressure of $3 \mathrm{mmHg}(0-5 \mathrm{mmHg})$ : IVC diameter $<21 \mathrm{~mm}+$

collapses $>50 \%$

Intermediate value: $8 \mathrm{mmHg}$ (range, 5-10 mmHg): $<21 \mathrm{~mm}$ and $<50 \%$ - High RA pressure of $15 \mathrm{mmHg}$ (range, $10-20 \mathrm{mmHg}):>21 \mathrm{~mm}+$ collapses
$<50 \%$

RA pressure

RVSP pulmonary systolic TV velocity $>2.8-2.9 \mathrm{~m} / \mathrm{s}=$ SPAP $36 \mathrm{mmHg}$ (RA pressure $3-5 \mathrm{mmHg}$ )
- Good correlation with CMR derived RVEF

Reflects both longitudinal and radial contraction

- Reliable

Reproducible

- Do not require full visualization of the RV

- Tissue doppler is less load dependen

- Clinically useful

Image quality, delineation between endocardium and trabeculations - Contribution of RVOT to overall systolic function

- Image quality

- Load dependency

- Requires offline analysis and experience

- Irregular heart rates

- RA pressure is elevated (IVRT is decreased)

- Effects of age, respiration, heart rate and loading conditions

correlate well with hemodynamic parameters

Early and more easily quantifiable marker of subclinical RV dystunction (vilation)
dilatation

- Markers of RA dilatation - sign of volume - or pressure

overload

- Easily obtained

PA area better indicator for RV diastolic dysfunction

- Underestimated with 2D compared with 3D

- Assumes symmetrical shape of the cavily

- Normal values not well established

- Single plane volume calculation may be inaccurate (RA enlargement is

- RA area more time-consuming

- Easily obtained from subcostal window

IVC collapse cannot be used to estimate RA pressure in ventilated

patients

- Hepatic vein flow velocities have been validated in mechanically ventilated patients

Independent predictor for mortality/HF/ sudden death/stroke after myocardial infarction, post-cardiac surgery, PAHpatients

Prognostic value not established

Prognostic value not established

Independent predictor of mortality (27)

Elevated RA pressure is a predictor for mortality

Prognostic value unknown

- No significant RVOT obstructions

A

- SPAP increose with age and pressury

- Elevated SPAP may not always indicate elevated PVR

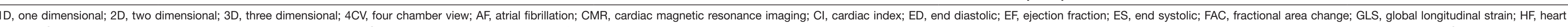

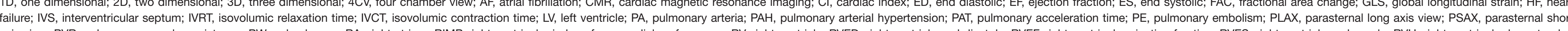

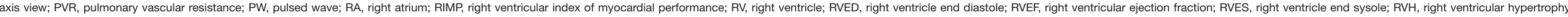

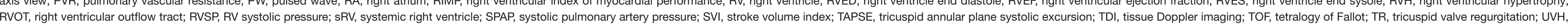
univentricular heart; Vs, systolic hepatic vein flow; Vd, diastolic hepatic vein flow. 
to the ERS/ERC guidelines as a mean PA pressure $\geq 25 \mathrm{mmHg}$ (30) on right heart catheterization [now defined by the latest ERS guidelines of 2019 as a mean PA pressure $>20 \mathrm{mmHg}$ (31)]. Diagnosing $\mathrm{PH}$ is important, given that these patients may benefit from PH-specific therapy. Patients with signs or suspicion of $\mathrm{PH}$ require further investigation, including cardiac catheterization (for determination of precapillary $v s$. postcapillary etiology of PH) (29). For CHD patients with associated pulmonary arterial hypertension (PAH) there are 4 subgroups [Eisenmenger syndrome, systemic-to-pulmonary shunts (correctable and non-correctable), small (incidental) defects and after corrective cardiac surgery $(32,33)]$. In case of small defects (VSD $<1 \mathrm{~cm}$ and ASD $<2 \mathrm{~cm}$ assessed by echo), the defect itself do not account for the development of elevated PVR and the clinical picture is very similar to idiopathic PAH. The size of small/coincidental defects applies to adult patients. Furthermore, the simple diameter may be not sufficient for defining the hemodynamic relevance of the defect, the pressure gradient, the shunt size and direction and the pulmonary to systemic flows ratio $(\mathrm{Qp} / \mathrm{Qs})$ should be considered (33).

\section{Evaluation of RV function by CMR imaging}

CMR has become an invaluable imaging tool in CHD and allows 3D anatomical reconstruction of very good quality as it is not limited by acoustic window, body size or exposure to harmful ionizing radiation. Besides the feasibility of a more detailed anatomical reconstruction, CMR is also useful for volumetric measurements, the assessment of myocardial fibrosis, the ability to evaluate the great vessels, and flow-related parameters in the pulmonary artery (PA) $(34,35)$. According to the ESC recommendations, CMR in CHD patients with $R V$ disease should be performed for (I) quantification of RV volumes, right ventricle ejection fraction (RVEF), (II) evaluation of the RVOT, PA and PA conduits, (III) quantification of PR, (IV) evaluation of systemic and pulmonary veins, $(\mathrm{V})$ quantification of myocardial mass (LV and RV), (VI) detection and quantification of myocardial fibrosis/scar (gadolinium late enhancement) and tissue characterization (fibrosis, fat, iron, etc.). As a result of late gadolinium enhancement or more recent T1 mapping (36), scar tissue or diffuse myocardial fibrosis (12) can be identified and quantified. It has been reported that myocardial fibrosis has diagnostic (37) and prognostic values (38), although in some patients, like in those with $\mathrm{PH}, \mathrm{RVEF}$ remains the strongest predictor of mortality (39). A large RV volume, a reduced RVEF (<45\%) and reduced $L V$ volume are considered to be signs of RV dysfunction on CMR. Moreover, these variables have been identified as independent predictors of mortality and prognosis particularly in adult patients with $\mathrm{PH}$ (35). CMR angiography is mainly used for the visualization of the PA, the aorta and the systemic and pulmonary veins. A detailed CMR protocol in the patient with $\mathrm{PH}$ is provide elsewhere (40). When CMR mass and volume imaging is combined with TWIST (time-resolved angiography with stochastic trajectories), regional and global pulmonary arterial perfusion can be quantified (41).

\section{Evaluation of the RV by computed tomography}

Thanks to the excellent spatial resolution and rapid acquisition time, computed tomography (CT) imaging plays an important role for CHD patients and, besides the heart, can assess lung parenchymal disease and mediastinal structures in a single, fast acquisition. Yet it is less frequently used than echocardiography and CMR imaging due to the exposure to ionizing radiation and the need for radiocontrast agents in most cases (35). However, CT scan is the first-choice imaging technique in patients with limited acoustic window where more detailed anatomical information is needed or for patients who are unable to undergo CMR imaging. Other limitations of CT include lower soft tissue and temporal resolutions and lack of hemodynamic assessment (12). According to the ESC guidelines and a review paper on right heart imaging in CHD (34,35), CT imaging is superior for (I) evaluation of collaterals and arteriovenous malformations, (II) coronary anomalies, coronary kinking and coronary artery disease, (III) detection of intra- and extracardiac masses, (IV) the assessment of great vessels, (V) the visualization of the proximal and distal PA anatomy and the presence of obstruction or thrombosis (not uncommon in Eisenmenger patients) and (VI) the evaluation of the patency of palliative (e.g., Blalock-Taussig) shunts. A sign of pressure overload of the RV on CT is ventricular septal shifting to the LV and is considered predictive of short-term mortality in patients with severe pulmonary embolism (PE) (42). Finally, the direction of intra- or extracardiac shunting can be determined based on the flow direction of the contrast (35).

\section{Cardiac catbeterization and $R V$ function}

In the work-up of RV failure, cardiac catheterization is 
not only important for assessment of PVR, pulmonary capillary wedge pressure (PCWP), LV and RV end-systolic and end-diastolic pressures, pressure gradients and shunt quantifications, but also for immediate therapeutic decision making (34). In patients with $\mathrm{PAH}$ simultaneous pressure measurements might give more detailed information as also acute vasoreactivity testing does. The additional strengths of catheterization are accurate visualization of stented structures, the presence of collateral arteries, surgical shunts, arteriovenous malformations and coronary artery disease (12). Coronary angiography may be performed for TGA patients after arterial switch repair with signs of ischemia due to the high risk of coronary kinking, ruling out coronary malperfusion as a cause for RV failure and is an alternative to CT angiography. Regular coronary angiography is also important after heart transplantation (HT) to monitor for coronary allograft vasculopathy (CAV) (43).

Finally, the ratio between RV contractility and PA afterload-so-called RV-PA coupling-is a sensitive metric for detection RV dysfunction. RV-PA coupling is best described by the ratio of RV end-systolic elastance (Ees) to PA effective arterial elastance (Ea) (44). An RV-PA coupling ratio, or Ees/Ea, of 1.5-2.0 is consistent with maximal efficiency of the system (hydraulic work versus oxygen consumption), conversely the RV-PA unit is considered uncoupled when the Ees/Ea ratio remains $<1.0(45,46)$. The gold standard measurement of RV-PA coupling, and one which is infrequently used in clinical practice, utilizes a conductance catheter to simultaneously measure RV pressure and volume, creating a multi-beat family of RV PV loops.

In the work-up of RV failure, one should look for $\mathrm{PH}$ [now defined by the latest ERS guidelines of 2019 as a mean PA pressure $>20 \mathrm{mmHg}$ (31)]. In the case of precapillary $\mathrm{PH}$ (defined by concomitant presence of $\mathrm{mPAP}>20 \mathrm{mmHg}$, $\mathrm{PAWP} \leq 15 \mathrm{mmHg}$ and $\mathrm{PVR} \geq 3 \mathrm{WU}$ ), $\mathrm{PH}$-specific therapy is indicated (30).

\section{Electrocardiogram (ECG)}

Typical ECG signs of subpulmonary RV failure, with or without cor pulmonale, are right axis deviation, $\mathrm{RV}$ hypertrophy, P pulmonale pattern, low-voltage QRS and incomplete or complete right bundle branch block. RV dilatation provides the substrate for electrical instability. A QRS width of $140 \mathrm{~ms}$ showed good sensitivity for a diagnosis of RV dilatation $(>80 \%)$ and dysfunction (>95\%) (47). Tachyarrhythmias or brady-arrhythmias can be a cause or result of RV failure. In addition, loss of sinus rhythm is associated with increased risk of adverse cardiac outcome. Furthermore, in CHD it is important to look for changes in ECG parameters as these patients often have wide and abnormal QRS-complexes from the beginning (48). Prolongation of the QRS duration with a rate of change $\geq 4 \mathrm{~ms} /$ year is associated with an increased risk of sustained ventricular tachycardia and sudden cardiac death in TOF patients (3).

More recently, there has been an emerging interest in QRS fragmentation. Fragmented QRS-complexes (fQRS) are caused by activation paths inside ventricular scars that are prone to re-entry circuits, hence a marker of inhomogeneous ventricular activation due to myocardial fibrosis (49). In ACHD patients, fibrosis and scar tissue occur, more often the result of surgery. Definition of fQRS is dependent of QRS duration (49). Fragmented QRS on 12-lead ECG has been associated with adverse outcome, ventricular arrhythmia and sudden cardiac death. These fQRS related complications are not only found in ischemic cardiomyopathy (50) but also in adults with TOF (51), after atrial switch repair for d-TGA (49), and in adults with Ebstein anomaly and larger atrialized RV area (52). In addition, the extent of fQRS was documented to be superior to QRS duration in predicting all-cause mortality. Fragmented QRS was independently associated with HF symptoms and impaired ventricular function, specifically in ACHD patients (53).

\section{Cardiac exercise stress testing}

\section{Cardiopulmonary exercise test (CPET)}

CPET is performed for objective assessment of exercise intolerance. Exercise capacity is reduced in ACHD patients (48) and reference values related to the anatomical cardiovascular defect have been published (54). The ventilatory efficiency (VE) slope $\left(\mathrm{VE} / \mathrm{VCO}_{2}\right)$ can be used to determine prognosis: a higher $\mathrm{VE} / \mathrm{VCO}_{2}$ slope has been associated with the presence of $\mathrm{PH}$ and $\mathrm{RV}$ dysfunction (55). In addition, both $\mathrm{VO}_{2}$ and $\mathrm{VE} / \mathrm{VCO}_{2}$ slope have been shown to be associated with New York Heart Association (NYHA) functional class and to be strong predictors of mortality (54). Thus, CPET is a valuable tool to determine prognosis in CHD patients with or without RV dysfunction $(48,56)$. However, exercise capacity differs significantly across the spectrum of ACHD: the more complex the congenital defect, the lower the peak $\mathrm{VO}_{2}$ and the higher the $\mathrm{VE} / \mathrm{VCO}_{2}$ slope (55). As a consequence of complexity, 
patients with a pressure or volume loaded $\mathrm{RV}$ might have clearly altered CPET results. Moreover, peak $\mathrm{VO}_{2}$ is an effort-dependent measure and not all ACHD patients reach their physiological maximum ( $R E R \geq 1.10)$ (55). Thus, we may need to search for alternative exercise parameters to evaluate the exercise tolerance. Parameters that correlate with peak $\mathrm{VO}_{2}$ such as oxygen uptake efficiency slope, as well as ventilatory anaerobic threshold and oxygen uptake versus exercise intensity slope can be useful (55). Furthermore, although there is a good correlation between CPET results and mortality $\left[\mathrm{VO}_{2}<15 \mathrm{~mL} / \mathrm{min} / \mathrm{kg}\right.$ (48)], there is no specific exercise variable that predicts RV failure.

\section{Imaging during exercise}

Stress protocols include exercise stress with treadmill or bicycle, and pharmacological stress, mainly with dobutamine (17). Stress imaging is mainly done by echocardiography or CMR. The strengths of stress-echo in CHD are its feasibility and safety as well as the possibility to assess perfusion reserve. Most frequent indication for stress echocardiography is the evaluation of ischemia, but the real clinical significance in ACHD is unknown. According to the American Society of Echocardiography (ASE) guidelines (16), a stress echocardiography should be performed in patients with dyspnea of unknown origin and to assess stress-induced PH. Potential indications for stress echocardiography in ACHD patients (exercise, pharmacological) include (I) evaluation of pulmonary vascular disease (PVD) (17), (II) timing of intervention, (III) evaluation of vascular obstructive disease such as in coarctation of the aorta, (IV) unmasking ventricular dysfunction in sRV, (V) detecting ischemia in the setting of coronary reimplantation and (VI) measuring gradients of obstructive lesions to guide management decisions $(16,57)$. Assessment of RV parameters during stress is of interest in several congenital anomalies as echocardiography provides the ability for quantification of pressures, systolic, and diastolic function. Stress echocardiography plays an important role for the evaluation of myocardial function in patients' status post arterial switch repair, that entails reimplantation of the coronary arteries. In relation to RV function, RVEF and TAPSE were reported to be lower in TGA patients after atrial switch repair versus ccTGA at rest, however no relationship could be documented between echocardiographic findings at rest and data obtained by exercise imaging (58). As a result, exercise imaging in general can play an important role in the evaluation of $\mathrm{RV}$ function, adding value to the standard resting data.
Exercise CMR has the ability to obtain 3D imaging of the $\mathrm{RV}$ throughout the whole cardiac cycle and during exercise, without the need to obtain arterial and central venous sampling. When compares with TTE, CMR provides a more complete description of ventricular filling, ejection and interventricular interaction by assessing changes in RV and LV volumes during exercise (59). Furthermore, exercise CMR provides much more geometric and morphometric information of the RV and pulmonary circulation than stress echocardiography (59). The sRV and its corresponding SV differ during exercise between d-TGA patients after atrial switch repair and patients with ccTGA (60). In general, exercise testing is much more physiological than pharmacological stress, as it induces also the preload of the ventricle. Pharmacological testing with inotropes increases the contractility and the heart rate but does not interfere with the ventricular preload. Therefore, if technically feasible, exercise testing is in most case preferred over pharmacological CMR or TTE stress testing.

\section{Biomarkers}

There is minimal data on biomarkers predicting $\mathrm{RV}$ dysfunction. We will discuss RV-specific biomarkers related to myocyte injury, stress and inflammation (61), currently used in clinical practice.

\section{Biomarkers of myocyte injury and stress}

\section{Natriuretic peptides}

Brain natriuretic peptide (BNP) and N-Terminal pro-brain natriuretic peptide (NT-proBNP) are golden standard biomarkers of heart failure predicting worse outcomes in patients without CHD. BNP and NT-proBNP have been tested in various CHD (48,62-64): (I) BNP is elevated in atrial and ventricular septal defects and strongly correlated with severity of shunt and PAH, (II) BNP correlates with the degree of RV dilatation, severity of pulmonary regurgitation and exercise capacity in tetralogy of Fallot (TOF), (III) BNP correlates with severity of tricuspid regurgitation and predicts heart failure, need for transplantation and death in systemic RV $(65,66)$. Increasing serum BNP levels are also independently associated with hyponatremia. Hyponatremia is present in $15.5 \%$ of ACHD patients, in particular those with congenitally corrected transposition, Fontan physiology and Eisenmenger syndrome, and carries a 3-fold high risk of death (67). 


\section{High sensitivity troponins (hsTns)}

HsTn is a marker for cardiomyocyte injury in acute coronary syndrome, myocarditis, tachyarrhythmias and stable and acute left heart failure predicting mortality and need for readmission. HsTn has also been used to predict adverse outcomes and RV dysfunction in acute PE (68) and in precapillary $\mathrm{PH}$ (69). In CHD patients, elevated level of hs $\mathrm{Tn}$ is associated with decreasing $\mathrm{RV}$ function in repaired TOF with volume overload (70), increasing RV end diastolic area in congenitally corrected transposition (71), poor clinical outcomes in patients with CHD-PH (72), might be even elevated in asymptomatic ACHD patients, but its significance is yet to be established (73). Therefore, it is recommended to screen hsTn in $\mathrm{PH}$-patients with NYHA III/IV (72). HsTn is elevated in patients with systemic RV dysfunction and may be a superior biomarker compared to NTproBNP (74). In addition, hsTn may be released due to supraventricular arrhythmia's, possibly a result of increased myocardial wall stress due to atrial stretch or micro-embolism causing myocardial ischemia.

\section{Type III collagen}

Circulating breakdown peptides of cardiac extra-cellular matrix, namely collagen I c-terminal telopeptide (CITP) and procollagen III N-terminal (PIIINP) are considered as biomarkers of cardiac fibrosis (75). However, Nagao et al. demonstrate a lack of correlation between circulating collagens I and III in heart failure and myocardial collagen mRNA expression (a surrogate for fibrosis) and suggest that decreased renal clearance contributes to the elevated circulating collagens (75). To the best of our knowledge, there are no studies investigating these markers in ACHD patients with right-sided heart failure. Increasing levels of circulating microRNA-21 correlated with increasing myocardial fibrosis and worsening RV function in TOF (76).

\section{Biomarkers of inflammation}

\section{Suppressor of Tumorgenicity 2 (ST2) and Soluble ST2 (sST2)}

ST2 is a member of the IL-1 receptor family and binds to IL-33 leading to decreased fibrosis and hypertrophy.
Though the heart, endothelium, and leukocytes express components of ST2/ST2L/IL-33 pathway, the source of circulating serum ST2 is extra-myocardial. Elevated levels of sST2 predict a poor prognosis in left ventricular heart failure (recommendation class IIb) (77), but elevated levels are now also being noted in response to $\mathrm{RV}$ congestion $(78,79)$. No data exists on the role of ST2 and sST2 in RV specific conditions such as in predicting $\mathrm{PH}$ disease severity and risk stratifying ACHD patients.

\section{Galactin-3}

Galactin-3 (gal-3) is a $\beta$-galactoside-binding lectin. Its expression is increased in activated macrophages, smooth muscle cells and fibroblasts. Gal-3 plays an important role in pathways that regulate cardiac contractility and inflammatory cascades following injury (61); Gal-3 stimulates remodeling, fibroblast proliferation, collagen deposition, and ultimately fibrosis in the heart and arteries (80). Gal-3 acts downstream of aldosterone and is an established biomarker for cardiac fibrosis (81). Consequently, Gal-3 has been approved by the US Food and Drug Administration as a new biomarker for additive risk stratification in HF. Serum Gal-3 also correlates well with RV function and/or NYHA class in the context of isolated $\mathrm{PH}$ and is a strong predictor of mortality and recurrent HF $(81,82)$. According to Geenen et al., Gal-3 may be a better predictor for adverse cardiac outcome than NT-proBNP in the sRV (62). On the other hand, in patients with systemic sclerosis, the longitudinal peak systolic strain rate correlated negatively with Gal-3 (83).

Furthermore, two fibrosis biomarkers, Gal-3 and ST2, provide prognostic value additive to natriuretic peptides and traditional risk factors in HF patients. So, combination of biomarkers involving heterogeneous fibrosis pathways may identify patients with high systemic fibrosis, providing powerful risk stratification value (84).

\section{Growth differentiation factor 15 (GDF-15)}

GDF-15 is a stress-responsive cytokine expressed in the cardiovascular system and integrates information from cardiac and extracardiac disease pathways linked to incidence, progression and prognosis of HF: increased 
plasma levels of GDF-15 (after myocardial infarction) are associated with an increased risk of $\mathrm{HF}$, independent of BNP levels, and disease severity (NYHA class). Circulating GDF15 is associated with adverse outcomes in cardiovascular disease (85). GDF-15 is prognostic in acute or chronic right-sided $\mathrm{HF}$ and remained an independent predictor of outcome after adjustment for RV function, NT-proBNP and troponin $T$ in patients with acute PE (86). GDF-15 has been reported to be an independent prognostic biomarker in patients with idiopathic PAH and right-sided HF (87) and levels of GDF-15 were related to clinical (NYHA class, 6-minute-walk distances), hemodynamic (mean RA and PCWP, lower $\mathrm{SvO}_{2}$ ) and biochemical indicators (levels of creatinine, uric acid, NT-proBNP) of more severe disease. According to Geenen et al., GDF-15 can be a potential marker for risk stratification but the assay currently is quite expensive (62). In addition, GDF-15 seems to be a better predictor for adverse outcomes [mortality, atrial fibrillation (AF), acute or chronic HF, coronary artery disease] than NT-proBNP in patients with sRV (62).

\section{How to treat RV dysfunction in CHD?}

As a result of the broad spectrum of ACHD, general ACHD-specific recommendations for HF therapy are very difficult. With age, the risk of HF increases and depends on underlying anatomy: sRV carries a higher risk. The ACHD-HF phenotype differs from that of general adult HF population: extrapolation of HF therapies from nonCHD populations should be done with extreme caution. Treatment consists of percutaneous intervention for correctable causes, physical rehabilitation, initiation of drug therapy, device therapy and assist device implantation or HT. Treatment strategies for RV dysfunction and failure in $\mathrm{PAH}$, irrespective of the presence of $\mathrm{CHD}$, are outlined elsewhere in this special issue (see Inampudi et al., CDT 2020 in this special issue, article in press).

\section{Structural treatment}

\section{Pressure loaded RV}

The pressure-overloaded RV will eventually progress to various degrees of dysfunction and failure. In patients with TOF, percutaneous or surgical intervention of pulmonary stenosis (PS) offer the best chance of improving ventricular function (88). On the other hand, pulmonary outflow obstruction can protect against HF in unrepaired ccTGA (S.L.L. TGA) by reducing systemic atrioventricular valve regurgitation (increased LV afterload reduces IVS shift into the $L V$ ) and slower progression to sRV dysfunction. In addition, in ccTGA (S.L.L. TGA), pulmonary outflow obstruction is associated with an improved event-free survival $(34,89,90)$.

\section{Volume loaded RV}

In CHD patients with subpulmonary RV and volume overload (i.e., patients with Ebstein anomaly or PR after TOF repair), timely valve surgery or percutaneous valve implantation should be considered (88,91-93). In ccTGA patients of after Mustard/Senning repair, TV is the systemic valve and is prone to regurgitation, associated with RV failure and decreased survival. TV surgery can stabilize RV function and improve HF and these patients should be referred timely for surgery to improve outcome $(94,95)$.

\section{Pharmacological treatment}

Symptomatic patients with ACHD have neurohormonal activation of the natriuretic, endothelin, sympathoadrenergic, and renin-angiotensin-aldosterone systems (RAAS) (96). In general, the 2016 ESC HF guidelines suggest that standard HF treatment (diuretics, RAASblockers, beta-blockers, and mineralocorticoid receptor antagonists) can be used in ACHD patients with evidence of RV dysfunction (48).

\section{Subpulmonary RV}

Evidence for drug-therapies in the subpulmonary RV is lacking (97). In patients after TOF repair, increased sympathetic nervous system activity has been described (98). Yet, the beneficial effects of RAAS blockade or betablockers have yet to be demonstrated in right-sided HF (48). Recently the REDEFINE trial showed there was no beneficial effect of losartan on RV dysfunction or secondary outcome in adults after repaired TOF (99). For asymptomatic patients lacking any clinical signs of HF, no medical treatment is indicated. Loop diuretics may be indicated in adults with RV failure, according to preload conditions, CVP, and liver size (100).

Of note, in children and young adults with biventricular circulation, RV and LV failure are rarely associated with typical adult clinical signs such as leg edema or orthopnea. Moreover, the pressure overloaded RV, especially in young patients, is often very preload dependent so that loop diuretics, if at all, must be used with caution $(100,101)$. One randomized controlled study (102) suggested that 
ACE-inhibition (ramipril) in the volume overloaded RV after repair of TOF may benefit long-axis function and improve biventricular function. In case of pressure-overload due to precapillary $\mathrm{PH}$, $\mathrm{PAH}$-targeted drug therapy is recommended (97).

\section{Systemic RV}

Extrapolation of the 2016 ESC HF guidelines in patients with an sRV is more difficult. In most cases, RV dysfunction by non-invasive imaging precedes the onset of clinical HF. There is no clear EF cut-off value that defines abnormal EF in $\mathrm{sRV}$, so it is unclear when pharmacotherapy should be initiated, especially in asymptomatic CHD patients. HF is a strong predictor for mortality in TGA patients (Mustard/ Senning and ccTGA) (103) and clinical outcomes are strongly associated with the presence and severity of TR. As mentioned above, BNP correlates with functional status, RVEF, exercise intolerance and TR severity, but a cut-off value to start therapy is not known. Although conventional HF therapy has been used in patients with sRV dysfunction, due to a lack of data specific to this population, the efficacy of standard HF therapy still remains unclear (104). ACEinhibitors and beta-blockers are controversial (88), and their use is not recommended in asymptomatic patients $(48,105)$. In symptomatic patients, ACE-inhibitors or ARBs are often not used because of a (I) lack of evidence, and (II) to secure blood pressure that permits beta-blockade for management of arrhythmia (66). An overview of tested medical treatment for HF in sRV is summarized in Table 3. In Table 4 we summarize the evidence of the treatment of sRV failure.

Furthermore, subpulmonary LV dysfunction is associated with severity of HF in patients with sRV. Therefore, in symptomatic patients with assumed neurohormonal activation, standard HF treatment can be considered. Overall, given the lack of evidence, these patients may require other therapies including HT (104).

\section{Electrical optimization}

\section{Ablation}

Arrhythmias in ACHD are a consequence of multiple factors: congenital anatomical heart defect, surgical scarring, hypoxemia, hemodynamics sequelae and genetic factors (124). Atrial arrhythmias are not well tolerated in (66) patients with $2 \mathrm{~V}-\mathrm{RV}$ and $1 \mathrm{~V}$ circulation and radiofrequency ablation of these arrhythmias was more frequently required. Hemodynamic assessment is suggested in any new-onset or worsening arrhythmia (124). In order to restore the hemodynamics, ablation can be beneficial, especially in patients with Ebstein anomaly with ventricular preexcitation, and any atrial arrhythmias in patients susceptible to hemodynamic instability and sudden death, i.e., sRV post atrial switch repair, Fontan circulation and Eisenmenger syndrome (124).

\section{CRT-D, CRT-P and ICD}

The role of cardiac resynchronization therapy (CRT) is well known in LV dyssynchrony, but for RV failure its value is uncertain, mainly due to the heterogeneity of the underlying anatomy (48). ACHD patients with a systemic LV, prolonged QRS duration (LBBB $\geq 120 \mathrm{~ms}$ or non-LBBB) and LV (LVEF <40\%) or RV dysfunction (RV FAC <35\%) were most likely to respond to CRT with an improvement in functional NYHA class in early and late follow-up, whereas systemic LV size and LV function only improved at late follow-up (125). Experience with CRT patients with a sRV is limited. To our knowledge, the largest study to date was published in 2005, included 17 patients and showed a significant increase in systemic ventricular EF and decrease in QRS duration (126). CRT of the sRV may improve HF symptoms but the optimal location for lead placement still remains unclear (127). Chronic subpulmonary LV pacing in patients with ccTGA results in clinical deterioration (128).

\section{Mechanical circulatory support/pumps (MCS)}

Despite comorbidities and anatomical constraints, mechanical support can be successfully used in CHD patients with sRV failure $(129,130)$ as destination or bridging therapy to HT (123). In many cases, though, implantation of MCS remains the only option in the management of endstage HF (88). In young TGA (Mustard/Senning or ccTGA) patients, a ventricular assist device may be a feasible and well tolerated option for bridge to transplantation (131). But after implantation of MCS, patients with ACHD have a lower probability of receiving a $\mathrm{HT}$ when compared to patients without ACHD (88). A higher mortality and morbidity have been detected in patients with MCS as a bridge to HT, and these patients have been associated with worse functional status, increased infection rate and increased duration of ventilatory support after transplantation (132). A RV assist device in case of failing subpulmonary RV (TOF repair, $\mathrm{PH}$ ) can be considered but data are lacking (133). In animal models, a RV assist device was shown to unload the chronic pressure-overloaded RV, improved cardiac output and after 8 weeks RV hemodynamic recovery and reverse remodeling began to occur (134). 


\begin{tabular}{|c|c|c|c|c|c|c|c|}
\hline Reference & Design & Population & $\mathrm{n}$ & Intervention & Duration & Comparison & Outcome \\
\hline \multirow[t]{2}{*}{ Hechter, 2001 (106) } & \multirow[t]{2}{*}{ Observational retrospective } & \multirow[t]{2}{*}{ TGA Mustard } & \multirow[t]{2}{*}{14} & \multirow[t]{2}{*}{ ACE-I } & \multirow[t]{2}{*}{2 years } & \multirow[t]{2}{*}{ Before and after ACE-I } & Positive: $\mathrm{VO}_{2}$ max exercise duration, $\mathrm{BP}$ at max exercise \\
\hline & & & & & & & Negative: exercise capacity and MRI measured EF \\
\hline Lester, 2001 (107) & $\mathrm{RCT} /$ crossover & TGA atrial switch & 7 & Losartan & 8 weeks & Placebo/crossover & Positive: exercise duration, TR, EF, systolic BP, exercise time \\
\hline \multirow[t]{2}{*}{ Robinson, 2002 (108) } & \multirow[t]{2}{*}{ Prospective cohort study } & \multirow[t]{2}{*}{ TGA atrial switch } & \multirow[t]{2}{*}{9} & \multirow[t]{2}{*}{ Enalapril } & \multirow[t]{2}{*}{12 months } & \multirow[t]{2}{*}{ Before and during ACE-I } & Positive: resting HR \\
\hline & & & & & & & Negative: exercise performance, cardiac index, $\mathrm{VO}_{2}$ (rest, peak), SVR \\
\hline \multirow[t]{2}{*}{ Dore, 2005 (109) } & \multirow[t]{2}{*}{ Multi-center RCT/double blind/crossover } & \multirow[t]{2}{*}{ TGA atrial switch } & \multirow[t]{2}{*}{29} & \multirow[t]{2}{*}{ Losartan } & \multirow[t]{2}{*}{15 weeks } & \multirow[t]{2}{*}{ Placebo/crossover } & Positive: none \\
\hline & & & & & & & Negative: exercise capacity, BNP \\
\hline Josephson, 2006 (110) & Retrospective observational cohort & & & & & & Negative: none \\
\hline Giardini, 2007 (111) & Prospective cohort study & ccTGA or TGA atrial & 8 & Carvedilol & 12 months & Before and after beta-blockade & Positive: RV and LV EF (MRI) biventricular remodeling, exercise duration \\
\hline & & & & & & & Negative: peak oxygen uptake \\
\hline Doughan, 2007 (112) & Retrospective cohort study & TGA atrial switch & 60 & Metoprolol Carvedilol & 4 months & Beta-blockade/no treatment & Positive: NYHA after start beta-blockade (within group) \\
\hline & & & & & & & Negative: RVEF, RV size, TR \\
\hline Khairy, 2008 (113) & Multi-center retrospective cohort study & TGA atrial switch & 37 & Beta-blockers & 3 years & Beta-blockade/no treatment & Positive: Lack of betablockers predicts appropriate shocks in patients with AICD \\
\hline & & & & & & & Negative: none \\
\hline Bouallal, 2010 (115) & Prospective cohort study & $\begin{array}{l}\text { ccTGA or TGA atrial } \\
\text { switch }\end{array}$ & 14 & Bisoprolol Carvedilol & 13 months & Before and after beta-blockade & Positive: NYHA, QoL, RVEF (radionuclide ventriculography) \\
\hline & & & & & & & Negative: RVEF and size (MRI) \\
\hline Tutarel, 2012 (116) & Retrospective observational control & TGA Mustard & 14 & Enalapril & 13 months & Before and after ACE-I & Positive: NT-proBNP \\
\hline & & & & & & & Negative: NYHA, exercise capacity \\
\hline Van Der Bom, 2013 (117) & Multi-center RCT/double blind & ccTGA or TGA atrial & 88 & Valsartan & 3 years & Valsartan/Placebo & Positive: RV volumes and mass (MRI), ventricular remodeling \\
\hline & & & & & & & $\begin{array}{l}\text { Negative: linical event rate, RV function (MRII), exercise capacity, TR, QoL, } \\
\text { neurohormonal activation, clinical outcome }\end{array}$ \\
\hline Dos, $2013(118)$ & $\mathrm{RCT}$, double blind & TGA atrial switch & 26 & Eplerenone & 12 months & Eplerenone/Placebo & Positive: Trend towards reduction in collagen turnover biomarkers (myocardial fibrosis) \\
\hline & & & & & & & Negative: RV mass and function, NT-proBNP \\
\hline Sohdi (119), 2018 & single-center prospective, randomized, & TOF or TGA & 17 & Eplerenone & 12 months & 3 months before or after drug-free period & Positive: none \\
\hline & open-label pilot study & & & & & & Negative: serum levels of PINP, PIIINP or gal-3, 6MWD or QoL \\
\hline van Dissel (120), 2019 & Multi-center RCT & cCTGA or TGA atrial & 88 & Valsartan & 3 years & Valsartan/placebo & Positive: decreased risk of events in symptomatic patients \\
\hline & & switch & & & & & Negative: survival \\
\hline
\end{tabular}

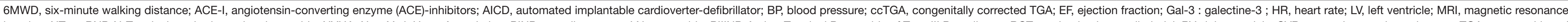

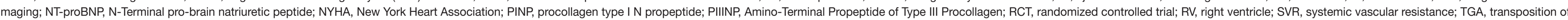
the great arteries; TOF, tetralogy of Fallot; TR, tricuspid regurgitation; QoL, quality of life. 
Table 4 Evidence in heart failure treatment for sRV in CHD

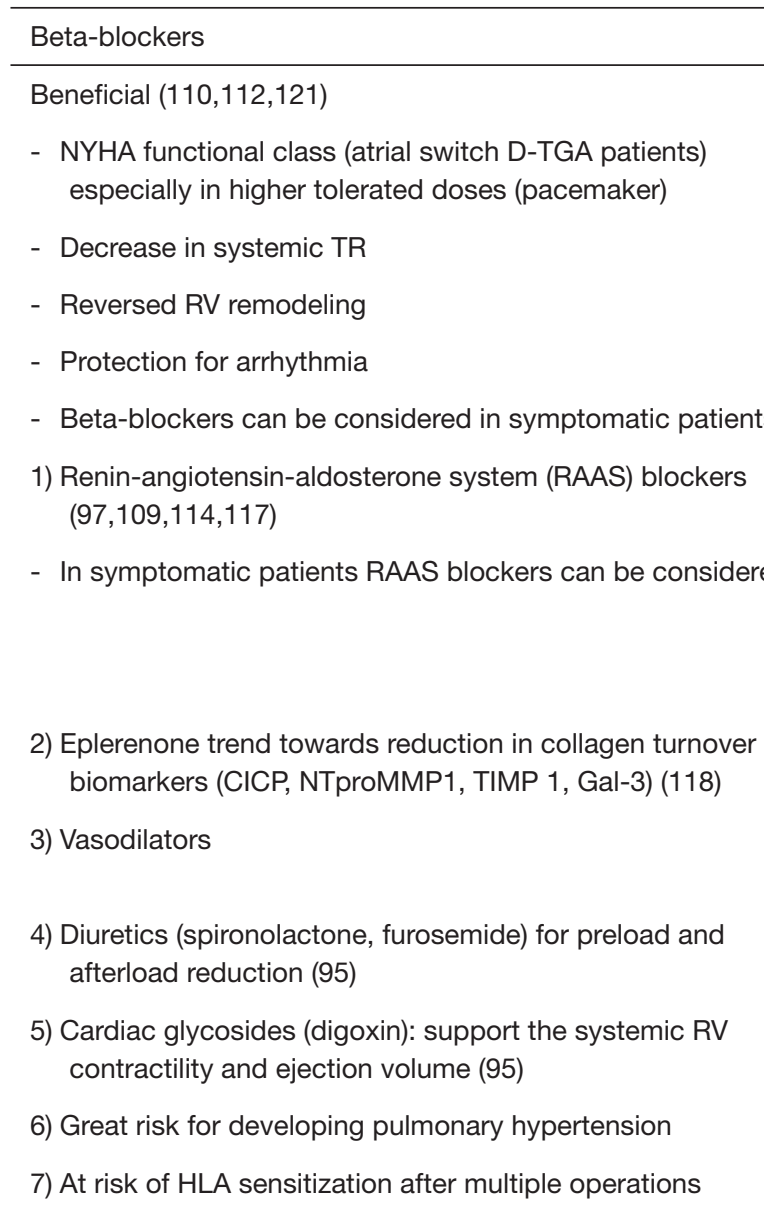

6MWD, six-minute walking distance; cc-TGA, congenitally corrected TGA; CHD, congenital heart disease; CICP, C-terminal propeptide of type I procollagen; D-TGA, dextro transposition of the great arteries; Gal-3, galectine-3; HLA, human leukocyte antigen; NTproMMP1, N-terminal pro matrix metalloproteinase 1; NYHA, New York heart association; PINP, procollagen type I N propeptide; PIIINP, AminoTerminal Propeptide of Type III Procollagen; RAAS, renin-angiotensin-aldosterone system; sRV, systemic right ventricle; RV, right ventricle; TR, tricuspid regurgitation; TIMP 1, tissue inhibitor of metalloproteinase-1; QoL, quality of life.

\section{HT}

HT is feasible for CHD patients but is often challenging due to complex intrathoracic anatomy, HLA sensitization, multi-organ involvement and abnormal hemodynamics (88). ACHD patients represent $\pm 10 \%$ of HT indications in patients of $18-30$ years $(135,136)$ and survival at 10 years is similar between ACHD and non-ACHD population. Nonetheless, earlier referral is important for advanced $\mathrm{HF}$ evaluation, but timing of initial assessment remains challenging. Although, parameters such as CPET results, hospitalizations, arrhythmia, symptomatic HF, proteinlosing enteropathy and plastic bronchitis may guide the decision (48), careful pre-transplant assessment is crucial.
Disadvantageous $(97,112,118,122)$

- Bradycardia or conduction abnormalities (ccTGA)

- Hospital admission rate, sudden cardiac death and mortality

- Harmful in baffle stenosis or restrictive ventricular physiology

- In stable, asymptomatic patients no benefit on clinical outcome, RV function or on exercise capacity

- Reduction in afterload in Fontan patients may compromise systemic venous return and cardiac output (123)

No beneficial effect on PINP, PIIINP or gal-3, 6MWD or QoL (119)

may compromise systemic venous return and cardiac output in Fontan patients (123)

- Very few data supporting its use

- Risk of bradyarrhythmia's and atrioventricular block

\section{Bilateral lung transplantation with progressive $\mathbf{P H}$}

$\mathrm{PH}$ is a common finding in patients with $\mathrm{sRV} \pm 10 \%$ $(104,136,137)$. Both precapillary and postcapillary PH are found but postcapillary $\mathrm{PH}$ is more common in patients with a progressive failing RV. Criteria for listing patients for combined heart and lung transplant versus HT alone, remains unclear (104) and needs to be discussed multidisciplinary in expert centers. If the PVR remains low, isolated HT is still preferred because of better outcome in general. However, when the elevated PA pressures are mainly related to PVD, isolated lung transplantation might be an option as long as it is expected that the subpulmonary ventricle will recover (or the underlying CHD can be 
repaired). However, these patients have often undergone multiple operations, placing them at risk of HLA sensitization (66). Therefore, we would suggest a timely assessment for transplantation.

\section{Conclusions}

Risk stratification of sRV should include clinical variables (NYHA class, blood pressure, echocardiographic findings) and biomarkers (NT-proBNP and GDF-15). Overall, drug therapy management of RV failure is still empiric and recommendations are mainly based on expert opinion. Besides drug therapy, hemodynamic, structural or device therapy are an important spectrum in the management of pressure/volume loaded RV.

\section{Acknowledgments}

Funding: None.

\section{Footnote}

Provenance and Peer Review: This article was commissioned by the Guest Editors (Martin Koestenberger, HarmJan Bogaard and Georg Hansmann) for the series "Right Ventricular Dysfunction" published in Cardiovascular Diagnosis and Therapy. The article was sent for external peer review organized by the Editor-in-Chief and the editorial office.

Conflicts of Interest: All authors have completed the ICMJE uniform disclosure form (available at http://dx. doi. org/10. 21037/cdt-20-370). The series "Right Ventricular Dysfunction" was commissioned by the editorial office without any funding or sponsorship. GH and MK served as the unpaid Guest Editors of the series. GH reports grants from German Research Foundation, Federal Ministry of Education and Research and from European Pediatric Pulmonary Vascular Disease Network, outside the submitted work. MD reports grants from Actelion/Johnson \& Johnson, grants and personal fees from Merck Sharp \& Dohme, grants and personal fees from Glaxo Smith Kline, grants from United Therapeutics, and grants from Ferrer group, outside the submitted work. WB reports other from Abbott and Occlutech, outside the submitted work. The authors have no other conflicts of interest to declare.

Ethical Statement: The authors are accountable for all aspects of the work in ensuring that questions related to the accuracy or integrity of any part of the work are appropriately investigated and resolved.

Open Access Statement: This is an Open Access article distributed in accordance with the Creative Commons Attribution-NonCommercial-NoDerivs 4.0 International License (CC BY-NC-ND 4.0), which permits the noncommercial replication and distribution of the article with the strict proviso that no changes or edits are made and the original work is properly cited (including links to both the formal publication through the relevant DOI and the license). See: https://creativecommons.org/licenses/by-nc-nd/4.0/.

\section{References}

1. Friedberg MK, Redington AN. Right versus left ventricular failure: differences, similarities, and interactions. Circulation 2014;129:1033-44.

2. Ho SY, Nihoyannopoulos P. Anatomy, echocardiography, and normal right ventricular dimensions. Heart 2006;92 Suppl 1:i2-13.

3. Alonso-González R, Dimopoulos K, Ho S, et al. The right heart and pulmonary circulation (IX). The right heart in adults with congenital heart disease. Rev Esp Cardiol 2010;63:1070-86.

4. Pettersen E, Helle-Valle T, Edvardsen T, et al. Contraction pattern of the systemic right ventricle shift from longitudinal to circumferential shortening and absent global ventricular torsion. J Am Coll Cardiol 2007;49:2450-6.

5. Sheehan F, Redington A. The right ventricle: anatomy, physiology and clinical imaging. Heart 2008;94:1510-5.

6. Szabó G, Soós P, Bährle S, et al. Adaptation of the right ventricle to an increased afterload in the chronically volume overloaded heart. Ann Thorac Surg 2006;82:989-95.

7. Johnson RC, Datar SA, Oishi PE, et al. Adaptive right ventricular performance in response to acutely increased afterload in a lamb model of congenital heart disease: evidence for enhanced Anrep effect. Am J Physiol Heart Circ Physiol 2014;306:H1222-30.

8. Greyson CR. The right ventricle and pulmonary circulation: basic concepts. Rev Esp Cardiol 2010;63:81-95.

9. Schneider M, Binder T. Echocardiographic evaluation of the right heart. Wien Klin Wochenschr 2018;130:413-20.

10. Borgdorff MA, Dickinson MG, Berger RM, et al. Right 
ventricular failure due to chronic pressure load: What have we learned in animal models since the NIH working group statement? Heart Fail Rev 2015;20:475-91.

11. Tadic M, Pieske-Kraigher E, Cuspidi C, et al. Right ventricular strain in heart failure: Clinical perspective. Arch Cardiovasc Dis 2017;110:562-71.

12. Orwat S, Diller GP, Baumgartner H. Imaging of congenital heart disease in adults: choice of modalities. Eur Heart J Cardiovasc Imaging 2014;15:6-17.

13. Koestenberger M, Friedberg MK, Ravekes W, et al. NonInvasive Imaging for Congenital Heart Disease: Recent Innovations in Transthoracic Echocardiography. J Clin Exp Cardiolog 2012;Suppl 8:2.

14. Dutta T, Frishman WH, Aronow WS. Echocardiography in the Evaluation of Pulmonary Embolism. Cardiol Rev 2017;25:309-14.

15. Lang RM, Badano LP, Mor-Avi V, et al. Recommendations for cardiac chamber quantification by echocardiography in adults: an update from the American Society of Echocardiography and the European Association of Cardiovascular Imaging. Eur Heart J Cardiovasc Imaging 2015;16:233-70.

16. Rudski LG, Lai WW, Afilalo J, et al. Guidelines for the echocardiographic assessment of the right heart in adults: a report from the American Society of Echocardiography endorsed by the European Association of Echocardiography, a registered branch of the European Society of Cardiology, and the Canadian Society of Echocardiography. J Am Soc Echocardiogr 2010;23:685713; quiz 86-8.

17. Mcleod G, Shum K, Gupta T, et al. Echocardiography in Congenital Heart Disease. Prog Cardiovasc Dis 2018;61:468-75.

18. Nagata Y, Wu VC, Kado Y, et al. Prognostic Value of Right Ventricular Ejection Fraction Assessed by Transthoracic 3D Echocardiography. Circ Cardiovasc Imaging 2017;10:e005384.

19. Friedberg MK. Imaging Right-Left Ventricular Interactions. JACC Cardiovasc Imaging 2018;11:755-71.

20. Mertens L, Khairy P. Right ventricular diastolic function in congenital heart disease. Can J Cardiol 2013;29:755-6.

21. Cheung YF, Yu CKM, So EKF, et al. Atrial Strain Imaging after Repair of Tetralogy of Fallot: A Systematic Review. Ultrasound Med Biol 2019;45:1896-908.

22. Burgess MI, Mogulkoc N, Bright-Thomas RJ, et al. Comparison of echocardiographic markers of right ventricular function in determining prognosis in chronic pulmonary disease. J Am Soc Echocardiogr 2002;15:633-9.
23. Forfia PR, Fisher MR, Mathai SC, et al. Tricuspid annular displacement predicts survival in pulmonary hypertension. Am J Respir Crit Care Med 2006;174:1034-41.

24. Ghio S, Klersy C, Magrini G, et al. Prognostic relevance of the echocardiographic assessment of right ventricular function in patients with idiopathic pulmonary arterial hypertension. Int J Cardiol 2010;140:272-8.

25. Ghio S, Guazzi M, Scardovi AB, et al. Different correlates but similar prognostic implications for right ventricular dysfunction in heart failure patients with reduced or preserved ejection fraction. Eur J Heart Fail 2017;19:873-9.

26. Haeck ML, Scherptong RW, Marsan NA, et al. Prognostic value of right ventricular longitudinal peak systolic strain in patients with pulmonary hypertension. Circ Cardiovasc Imaging 2012;5:628-36.

27. Tei C, Dujardin KS, Hodge DO, et al. Doppler echocardiographic index for assessment of global right ventricular function. J Am Soc Echocardiogr 1996;9:838-47.

28. Koestenberger M, Apitz C, Abdul-Khaliq H, et al. Transthoracic echocardiography for the evaluation of children and adolescents with suspected or confirmed pulmonary hypertension. Expert consensus statement on the diagnosis and treatment of paediatric pulmonary hypertension. The European Paediatric Pulmonary Vascular Disease Network, endorsed by ISHLT and D6PK. Heart 2016;102 Suppl 2:ii14-22.

29. Dimopoulos K, Condliffe R, Tulloh RMR, et al. Echocardiographic Screening for Pulmonary Hypertension in Congenital Heart Disease: JACC Review Topic of the Week. J Am Coll Cardiol 2018;72:2778-88.

30. Hansmann G. Pulmonary Hypertension in Infants, Children, and Young Adults. J Am Coll Cardiol 2017;69:2551-69.

31. Simonneau G, Montani D, Celermajer DS, et al. Haemodynamic definitions and updated clinical classification of pulmonary hypertension. Eur Respir J 2019;53.

32. D'Alto M, Mahadevan VS. Pulmonary arterial hypertension associated with congenital heart disease. Eur Respir Rev 2012;21:328-37.

33. "2015 ESC/ERS Guidelines for the diagnosis and treatment of pulmonary hypertension. The Joint Task Force for the Diagnosis and Treatment of Pulmonary Hypertension of the European Society of Cardiology (ESC) and the European Respiratory Society (ERS)." Nazzareno Galiè, Marc Humbert, Jean-Luc Vachiery, 
Simon Gibbs, Irene Lang, Adam Torbicki, Gérald Simonneau, Andrew Peacock, Anton Vonk Noordegraaf, Maurice Beghetti, Ardeschir Ghofrani, Miguel Angel Gomez Sanchez, Georg Hansmann, Walter Klepetko, Patrizio Lancellotti, Marco Matucci, Theresa McDonagh, Luc A. Pierard, Pedro T. Trindade, Maurizio Zompatori and Marius Hoeper. Eur Respir J 2015; 46: 903-975. Eur Respir J 2015;46:1855-6.

34. Baumgartner H, Bonhoeffer P, De Groot NM, et al. ESC Guidelines for the management of grown-up congenital heart disease (new version 2010). Eur Heart J 2010;31:2915-57.

35. D'Alto M, Dimopoulos K, Budts W, et al. Multimodality imaging in congenital heart disease-related pulmonary arterial hypertension. Heart 2016;102:910-8.

36. Amsallem M, Kuznetsova T, Hanneman K, et al. Right heart imaging in patients with heart failure: a tale of two ventricles. Curr Opin Cardiol 2016;31:469-82.

37. Swift AJ, Rajaram S, Capener D, et al. LGE Patterns in Pulmonary Hypertension Do Not Impact Overall Mortality. JACC Cardiovasc Imaging 2014;7:1209-17.

38. Freed BH, Gomberg-Maitland M, Chandra S, et al. Late gadolinium enhancement cardiovascular magnetic resonance predicts clinical worsening in patients with pulmonary hypertension. J Cardiovasc Magn Reson 2012;14:11.

39. Baggen VJ, Leiner T, Post MC, et al. Cardiac magnetic resonance findings predicting mortality in patients with pulmonary arterial hypertension: a systematic review and meta-analysis. Eur Radiol 2016;26:3771-80.

40. Latus H, Kuehne T, Beerbaum P, et al. Cardiac MR and CT imaging in children with suspected or confirmed pulmonary hypertension/pulmonary hypertensive vascular disease. Expert consensus statement on the diagnosis and treatment of paediatric pulmonary hypertension. The European Paediatric Pulmonary Vascular Disease Network, endorsed by ISHLT and DGPK. Heart 2016;102 Suppl 2:ii30-5.

41. Schoenfeld C, Cebotari S, Hinrichs J, et al. MR Imagingderived Regional Pulmonary Parenchymal Perfusion and Cardiac Function for Monitoring Patients with Chronic Thromboembolic Pulmonary Hypertension before and after Pulmonary Endarterectomy. Radiology 2016;279:925-34.

42. Araoz PA, Gotway MB, Harrington JR, et al. Pulmonary embolism: prognostic CT findings. Radiology 2007;242:889-97.

43. Mehra MR, Crespo-Leiro MG, Dipchand A, et al.
International Society for Heart and Lung Transplantation working formulation of a standardized nomenclature for cardiac allograft vasculopathy-2010. J Heart Lung Transplant 2010;29:717-27.

44. Vonk Noordegraaf A, Westerhof BE, Westerhof N. The Relationship Between the Right Ventricle and its Load in Pulmonary Hypertension. J Am Coll Cardiol 2017;69:236-43.

45. Vonk Noordegraaf A, Chin KM, Haddad F, et al. Pathophysiology of the right ventricle and of the pulmonary circulation in pulmonary hypertension: an update. Eur Respir J 2019;53.

46. Fourie PR, Coetzee AR, Bolliger CT. Pulmonary artery compliance: its role in right ventricular-arterial coupling. Cardiovasc Res 1992;26:839-44.

47. Alonso P, Andrés A, Rueda J, et al. Value of the Electrocardiogram as a Predictor of Right Ventricular Dysfunction in Patients With Chronic Right Ventricular Volume Overload. Rev Esp Cardiol (Engl Ed) 2015;68:390-7.

48. Budts W, Roos-Hesselink J, Rädle-Hurst T, et al. Treatment of heart failure in adult congenital heart disease: a position paper of the Working Group of GrownUp Congenital Heart Disease and the Heart Failure Association of the European Society of Cardiology. Eur Heart J 2016;37:1419-27.

49. Helsen F, Vandenberk B, De Meester P, et al. Appearance of QRS fragmentation late after Mustard/Senning repair is associated with adverse outcome. Heart 2017;103:1036-42.

50. Gardner PI, Ursell PC, Fenoglio JJ, et al. Electrophysiologic and anatomic basis for fractionated electrograms recorded from healed myocardial infarcts. Circulation 1985;72:596-611.

51. Bokma JP, Winter MM, Vehmeijer JT, et al. QRS fragmentation is superior to QRS duration in predicting mortality in adults with tetralogy of Fallot. Heart 2017;103:666-71.

52. Park SJ, Chung S, On YK, et al. Fragmented QRS complex in adult patients with Ebstein anomaly and its association with arrhythmic risk and the severity of the anomaly. Circ Arrhythm Electrophysiol 2013;6:1148-55.

53. Vehmeijer JT, Koyak Z, Bokma JP, et al. Sudden cardiac death in adults with congenital heart disease: does QRScomplex fragmentation discriminate in structurally abnormal hearts? Europace 2018;20:f122-f8.

54. Kempny A, Dimopoulos K, Uebing A, et al. Reference values for exercise limitations among adults with congenital heart disease. Relation to activities of daily life- 
-single centre experience and review of published data. Eur Heart J 2012;33:1386-96.

55. Buys R, Cornelissen V, Van De Bruaene A, et al. Measures of exercise capacity in adults with congenital heart disease. Int J Cardiol 2011;153:26-30.

56. Inuzuka R, Diller GP, Borgia F, et al. Comprehensive use of cardiopulmonary exercise testing identifies adults with congenital heart disease at increased mortality risk in the medium term. Circulation 2012;125:250-9.

57. Lancellotti P, Pellikka PA, Budts W, et al. The Clinical Use of Stress Echocardiography in Non-Ischaemic Heart Disease: Recommendations from the European Association of Cardiovascular Imaging and the American Society of Echocardiography. J Am Soc Echocardiogr 2017;30:101-38.

58. Helsen F, De Meester P, Van De Bruaene A, et al. Right ventricular systolic dysfunction at rest is not related to decreased exercise capacity in patients with a systemic right ventricle. Int J Cardiol 2018;260:66-71.

59. La Gerche A, Claessen G, Van de Bruaene A, et al. Cardiac MRI: a new gold standard for ventricular volume quantification during high-intensity exercise. Circ Cardiovasc Imaging 2013;6:329-38.

60. Helsen F, Claus P, Van De Bruaene A, et al. Advanced Imaging to Phenotype Patients With a Systemic Right Ventricle. J Am Heart Assoc 2018;7:e009185.

61. Jabagi H, Mielniczuk LM, Liu PP, et al. Biomarkers in the Diagnosis, Management, and Prognostication of Perioperative Right Ventricular Failure in Cardiac Surgery-Are We There Yet? J Clin Med 2019;8:559.

62. Geenen LW, van Grootel RWJ, Akman K, et al. Exploring the Prognostic Value of Novel Markers in Adults With a Systemic Right Ventricle. J Am Heart Assoc 2019;8:e013745.

63. Eindhoven JA, van den Bosch AE, Boersma E, et al. The usefulness of brain natriuretic peptide in simple congenital heart disease - a systematic review. Cardiol Young 2013;23:315-24.

64. Eindhoven JA, van den Bosch AE, Jansen PR, et al. The usefulness of brain natriuretic peptide in complex congenital heart disease: a systematic review. J Am Coll Cardiol 2012;60:2140-9.

65. Van De Bruaene A, Toh N, Hickey EJ, et al. Pulmonary hypertension in patients with a subaortic right ventricle: prevalence, impact and management. Heart 2019;105:1471-8.

66. Van De Bruaene A, Hickey EJ, Kovacs AH, et al. Phenotype, management and predictors of outcome in a large cohort of adult congenital heart disease patients with heart failure. Int J Cardiol 2018;252:80-7.

67. Dimopoulos K, Diller GP, Petraco R, et al. Hyponatraemia: A strong predictor of mortality in adults with congenital heart disease. Eur Heart J 2010;31:595-601.

68. Daquarti G, March Vecchio N, Mitrione CS, et al. Highsensitivity troponin and right ventricular function in acute pulmonary embolism. Am J Emerg Med 2016;34:1579-82.

69. Torbicki A, Kurzyna M, Kuca P, et al. Detectable serum cardiac troponin $\mathrm{T}$ as a marker of poor prognosis among patients with chronic precapillary pulmonary hypertension. Circulation 2003;108:844-8.

70. Lai CT, Wong SJ, Ip JJ, et al. Plasma Levels of High Sensitivity Cardiac Troponin T in Adults with Repaired Tetralogy of Fallot. Sci Rep 2015;5:14050.

71. Kowalik E, Klisiewicz A, Kowalski M, et al. High-Sensitive Cardiac Troponin T and Systemic Right Ventricular Area Predict Outcomes in Adults With Congenitally Corrected Transposition. Can J Cardiol 2018;34:1129-36.

72. Schuuring MJ, van Riel AC, Vis JC, et al. High-sensitivity troponin $\mathrm{T}$ is associated with poor outcome in adults with pulmonary arterial hypertension due to congenital heart disease. Congenit Heart Dis 2013;8:520-6.

73. Eindhoven JA, Roos-Hesselink JW, van den Bosch AE, et al. High-sensitive troponin- $\mathrm{T}$ in adult congenital heart disease. Int J Cardiol 2015;184:405-11.

74. Kowalik E, Klisiewicz A, Rybicka J, et al. High sensitivity cardiac troponin $\mathrm{T}$ and systemic right ventricular function in adults with congenitally corrected transposition of the great arteries. Int J Cardiol 2017;241:168-72.

75. Nagao K, Inada T, Tamura A, et al. Circulating markers of collagen types I, III, and IV in patients with dilated cardiomyopathy: relationships with myocardial collagen expression. ESC Heart Fail 2018;5:1044-51.

76. Reddy S, Hu DQ, Zhao M, et al. miR-21 is associated with fibrosis and right ventricular failure. JCI Insight 2017;2:e91625.

77. Yancy CW, Jessup M, Bozkurt B, et al. 2017 ACC/ AHA/HFSA Focused Update of the 2013 ACCF/AHA Guideline for the Management of Heart Failure: A Report of the American College of Cardiology/American Heart Association Task Force on Clinical Practice Guidelines and the Heart Failure Society of America. Circulation 2017;136:e137-e61.

78. Broch K, Andreassen AK, Ueland T, et al. Soluble ST2 reflects hemodynamic stress in non-ischemic heart failure. Int J Cardiol 2015;179:378-84. 
79. Bartunek J, Delrue L, Van Durme F, et al. Nonmyocardial production of ST2 protein in human hypertrophy and failure is related to diastolic load. J Am Coll Cardiol 2008;52:2166-74.

80. Barman SA, Chen F, Li X, et al. Galectin-3 Promotes Vascular Remodeling and Contributes to Pulmonary Hypertension. Am J Respir Crit Care Med 2018;197:1488-92.

81. Calvier L, Legchenko E, Grimm L, et al. Galectin-3 and aldosterone as potential tandem biomarkers in pulmonary arterial hypertension. Heart 2016;102:390-6.

82. Fenster BE, Lasalvia L, Schroeder JD, et al. Galectin-3 levels are associated with right ventricular functional and morphologic changes in pulmonary arterial hypertension. Heart Vessels 2016;31:939-46.

83. Karadag DT, Sahin T, Tekeoglu S, et al. Evaluation of left and right ventricle by two-dimensional speckle tracking echocardiography in systemic sclerosis patients without overt cardiac disease. Clin Rheumatol 2020;39:37-48.

84. Wang CH, Yang NI, Liu MH, et al. Estimating systemic fibrosis by combining galectin-3 and ST2 provides powerful risk stratification value for patients after acute decompensated heart failure. Cardiol J 2016;23:563-72.

85. Wollert KC, Kempf T. Growth differentiation factor 15 in heart failure: an update. Curr Heart Fail Rep 2012;9:337-45.

86. Lankeit M, Kempf T, Dellas C, et al. Growth differentiation factor-15 for prognostic assessment of patients with acute pulmonary embolism. Am J Respir Crit Care Med 2008;177:1018-25.

87. Nickel N, Kempf T, Tapken H, et al. Growth differentiation factor-15 in idiopathic pulmonary arterial hypertension. Am J Respir Crit Care Med 2008; 178:534-41.

88. Opina AD, Franklin WJ. Management of Heart Failure in Adult Congenital Heart Disease. Prog Cardiovasc Dis 2018;61:308-13.

89. Helsen F, De Meester P, Van Keer J, et al. Pulmonary outflow obstruction protects against heart failure in adults with congenitally corrected transposition of the great arteries. Int J Cardiol 2015;196:1-6.

90. Warnes CA, Williams RG, Bashore TM, et al. ACC/ AHA 2008 guidelines for the management of adults with congenital heart disease: a report of the American College of Cardiology/American Heart Association Task Force on Practice Guidelines (Writing Committee to Develop Guidelines on the Management of Adults With Congenital Heart Disease). Developed in Collaboration With the
American Society of Echocardiography, Heart Rhythm Society, International Society for Adult Congenital Heart Disease, Society for Cardiovascular Angiography and Interventions, and Society of Thoracic Surgeons. J Am Coll Cardiol 2008;52:e143-e263.

91. Oosterhof T, van Straten A, Vliegen HW, et al. Preoperative thresholds for pulmonary valve replacement in patients with corrected tetralogy of Fallot using cardiovascular magnetic resonance. Circulation 2007;116:545-51.

92. Plessis J, Hascoët S, Baruteau A, et al. Edwards SAPIEN Transcatheter Pulmonary Valve Implantation: Results From a French Registry. JACC Cardiovasc Interv 2018;11:1909-16.

93. Biernacka EK, Rużyłło W, Demkow M. Percutaneous pulmonary valve implantation - state of the art and Polish experience. Postepy Kardiol Interwencyjnej 2017;13:3-9.

94. Koolbergen DR, Ahmed Y, Bouma BJ, et al. Follow-up after tricuspid valve surgery in adult patients with systemic right ventricles. Eur J Cardiothorac Surg 2016;50:456-63.

95. Filippov AA, Del Nido PJ, Vasilyev NV. Management of Systemic Right Ventricular Failure in Patients With Congenitally Corrected Transposition of the Great Arteries. Circulation 2016;134:1293-302.

96. Bolger AP, Sharma R, Li W, et al. Neurohormonal activation and the chronic heart failure syndrome in adults with congenital heart disease. Circulation 2002;106:92-9.

97. Brida M, Diller GP, Nashat H, et al. Pharmacological therapy in adult congenital heart disease: growing need, yet limited evidence. Eur Heart J 2019;40:1049-56.

98. Heng EL, Bolger AP, Kempny A, et al. Neurohormonal activation and its relation to outcomes late after repair of tetralogy of Fallot. Heart 2015;101:447-54.

99. Bokma JP, Winter MM, van Dijk AP, et al. Effect of Losartan on Right Ventricular Dysfunction: Results From the Double-Blind, Randomized REDEFINE Trial (Right Ventricular Dysfunction in Tetralogy of Fallot: Inhibition of the Renin-Angiotensin-Aldosterone System) in Adults With Repaired Tetralogy of Fallot. Circulation 2018;137:1463-71.

100. Kaestner M, Schranz D, Warnecke G, et al. Pulmonary hypertension in the intensive care unit. Expert consensus statement on the diagnosis and treatment of paediatric pulmonary hypertension. The European Paediatric Pulmonary Vascular Disease Network, endorsed by ISHLT and DGPK. Heart 2016;102 Suppl 2:ii57-66.

101.Hansmann G, Koestenberger M, Alastalo TP, et al. 2019 updated consensus statement on the diagnosis and 
treatment of pediatric pulmonary hypertension: The European Pediatric Pulmonary Vascular Disease Network (EPPVDN), endorsed by AEPC, ESPR and ISHLT. J Heart Lung Transplant 2019;38:879-901.

102. Babu-Narayan SV, Uebing A, Davlouros PA, et al. Randomised trial of ramipril in repaired tetralogy of Fallot and pulmonary regurgitation: the APPROPRIATE study (Ace inhibitors for Potential PRevention Of the deleterious effects of Pulmonary Regurgitation In Adults with repaired TEtralogy of Fallot). Int J Cardiol 2012;154:299-305.

103. Roche SL, Redington AN. Right ventricle: wrong targets? Another blow for pharmacotherapy in congenital heart diseases. Circulation 2013;127:314-6.

104.Friedberg MK, Reddy S. Right ventricular failure in congenital heart disease. Curr Opin Pediatr 2019;31:604-10.

105. Stout KK, Broberg CS, Book WM, et al. Chronic Heart Failure in Congenital Heart Disease: A Scientific Statement From the American Heart Association. Circulation 2016;133:770-801.

106. Hechter SJ, Fredriksen PM, Liu P, et al. Angiotensinconverting enzyme inhibitors in adults after the Mustard procedure. Am J Cardiol 2001;87:660-3, A11.

107.Lester SJ, McElhinney DB, Viloria E, et al. Effects of losartan in patients with a systemically functioning morphologic right ventricle after atrial repair of transposition of the great arteries. Am J Cardiol 2001;88:1314-6.

108. Robinson B, Heise CT, Moore JW, et al. Afterload reduction therapy in patients following intraatrial baffle operation for transposition of the great arteries. Pediatr Cardiol 2002;23:618-23.

109. Dore A, Houde C, Chan KL, et al. Angiotensin receptor blockade and exercise capacity in adults with systemic right ventricles: a multicenter, randomized, placebo-controlled clinical trial. Circulation 2005;112:2411-6.

110.Josephson CB, Howlett JG, Jackson SD, et al. A case series of systemic right ventricular dysfunction post atrial switch for simple D-transposition of the great arteries: the impact of beta-blockade. Can J Cardiol 2006;22:769-72.

111. Giardini A, Lovato L, Donti A, et al. A pilot study on the effects of carvedilol on right ventricular remodelling and exercise tolerance in patients with systemic right ventricle. Int J Cardiol 2007;114:241-6.

112. Doughan AR, McConnell ME, Book WM. Effect of beta blockers (carvedilol or metoprolol XL) in patients with transposition of great arteries and dysfunction of the systemic right ventricle. Am J Cardiol 2007;99:704-6.
113. Khairy P, Harris L, Landzberg MJ, et al. Sudden death and defibrillators in transposition of the great arteries with intra-atrial baffles: a multicenter study. Circ Arrhythm Electrophysiol 2008;1:250-7.

114. Therrien J, Provost Y, Harrison J, et al. Effect of angiotensin receptor blockade on systemic right ventricular function and size: a small, randomized, placebo-controlled study. Int J Cardiol 2008;129:187-92.

115. Bouallal R, Godart F, Francart C, et al. Interest of -blockers in patients with right ventricular systemic dysfunction. Cardiol Young 2010;20:615-9.

116. Tutarel O, Meyer GP, Bertram H, et al. Safety and efficiency of chronic ACE inhibition in symptomatic heart failure patients with a systemic right ventricle. Int J Cardiol 2012;154:14-6.

117.van der Bom T, Winter MM, Bouma BJ, et al. Effect of valsartan on systemic right ventricular function: a double-blind, randomized, placebo-controlled pilot trial. Circulation 2013;127:322-30.

118. Dos L, Pujadas S, Estruch M, et al. Eplerenone in systemic right ventricle: double blind randomized clinical trial. The evedes study. Int J Cardiol 2013;168:5167-73.

119. Sodhi SS, Zhang TJ, McDonald R, et al. Effects of eplerenone on markers of myocardial fibrosis, 6-minute walk distance, and quality of life in adults with tetralogy of Fallot and complete transposition of the great arteries. Proc (Bayl Univ Med Cent) 2018;31:12-9.

120.van Dissel AC, Winter MM, van der Bom T, et al. Longterm clinical outcomes of valsartan in patients with a systemic right ventricle: Follow-up of a multicenter randomized controlled trial. Int J Cardiol 2019;278:84-7.

121. Smit-Fun VM, Buhre WF. Heart Failure in Adult Patients with Congenital Heart Disease. Anesthesiol Clin 2019;37:751-68.

122.Agarwal A, Dudley CW, Nah G, et al. Clinical Outcomes During Admissions for Heart Failure Among Adults With Congenital Heart Disease. J Am Heart Assoc 2019;8:e012595.

123. Brida M, Diller GP, Gatzoulis MA. Systemic Right Ventricle in Adults With Congenital Heart Disease: Anatomic and Phenotypic Spectrum and Current Approach to Management. Circulation 2018;137:508-18.

124. Khairy P. Arrhythmias in Adults With Congenital Heart Disease: What the Practicing Cardiologist Needs to Know. Can J Cardiol 2019;35:1698-707.

125. Yin Y, Dimopoulos K, Shimada E, et al. Early and Late Effects of Cardiac Resynchronization Therapy in Adult Congenital Heart Disease. J Am Heart Assoc 
2019;8:e012744.

126. Dubin AM, Janousek J, Rhee E, et al. Resynchronization therapy in pediatric and congenital heart disease patients: an international multicenter study. J Am Coll Cardiol 2005;46:2277-83.

127. Moore JP, Gallotti RG, Shannon KM, et al. A minimally invasive hybrid approach for cardiac resynchronization of the systemic right ventricle. Pacing Clin Electrophysiol 2019;42:171-7.

128. Yeo WT, Jarman JW, Li W, et al. Adverse impact of chronic subpulmonary left ventricular pacing on systemic right ventricular function in patients with congenitally corrected transposition of the great arteries. Int J Cardiol 2014;171:184-91.

129. Joyce DL, Crow SS, John R, et al. Mechanical circulatory support in patients with heart failure secondary to transposition of the great arteries. J Heart Lung Transplant 2010;29:1302-5.

130.Shah NR, Lam WW, Rodriguez FH, et al. Clinical outcomes after ventricular assist device implantation in adults with complex congenital heart disease. J Heart Lung Transplant 2013;32:615-20.

131. Michel E, Orozco Hernandez E, Enter D, et al. Bridge to Transplantation With Long-Term Mechanical Assist Devices in Adults With Transposition of the Great

Cite this article as: Santens B, Van De Bruaene A, De Meester P, D'Alto M, Reddy S, Bernstein D, Koestenberger M, Hansmann G, Budts W. Diagnosis and treatment of right ventricular dysfunction in congenital heart disease. Cardiovasc Diagn Ther 2020;10(5):1625-1645. doi: 10.21037/cdt-20-370
Arteries. Artif Organs 2019;43:90-6.

132.Bryant R, Rizwan R, Villa CR, et al. Transplant Outcomes for Congenital Heart Disease Patients Bridged With a Ventricular Assist Device. Ann Thorac Surg 2018;106:588-94.

133. Crossland DS, Van De Bruaene A, Silversides CK, et al. Heart Failure in Adult Congenital Heart Disease: From Advanced Therapies to End-of-Life Care. Can J Cardiol 2019;35:1723-39.

134. Verbelen T, Claus P, Burkhoff D, et al. Low-flow support of the chronic pressure-overloaded right ventricle induces reversed remodeling. J Heart Lung Transplant 2018;37:151-60.

135.Lund LH, Edwards LB, Kucheryavaya AY, et al. The registry of the International Society for Heart and Lung Transplantation: thirty-first official adult heart transplant report--2014; focus theme: retransplantation. J Heart Lung Transplant 2014;33:996-1008.

136. Menachem JN. Advanced Heart Failure in the ACHD Population: Finding the Fellows' Role in a Growing Field. J Am Coll Cardiol 2017;69:1986-9.

137. Kim YY, Awh K, Acker M, et al. Pulmonary arterial hypertension in adults with systemic right ventricles referred for cardiac transplantation. Clin Transplant 2019;33:e13496. 